\title{
The Role of Lactate and Other Laboratory Markers on Detection of Subtle Myocardial Dysfunction in Critically ill Children
}

\author{
Munar Lubis*, Aridamuriany Dwiputri Lubis, Badai Buana Nasution \\ Department of Child Health, Faculty of Medicine, Universitas Sumatera Utara, Medan, Indonesia
}

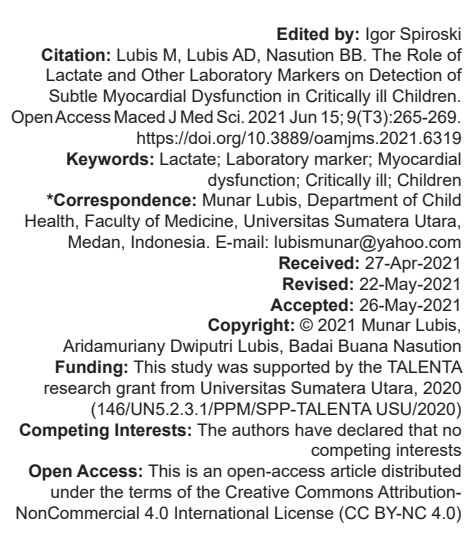

\section{Introduction}

Critically ill children have a high risk of developing life-threatening infections that can eventually lead to sepsis and multiorgan failure [1]. Sepsis is a serious infection that is a global problem with high morbidity and mortality [2]. Deaths due to sepsis occur around 4500 cases per year or about $7 \%$ of total child deaths [3], [4]. Under any critical circumstances, the cause is followed by a similar physiological and biochemical response, which is referred to as systemic inflammatory response syndrome. This response results in increased morbidity, including infection, multiorgan dysfunction, which often results in longer hospital stays and increased mortality [5]. Multiorgan failures that occur include the brain, kidneys, liver, and cardiovascular system. The cardiovascular system involvement could increase the mortality rate by $70-90 \%$. Cardiovascular disorders in sepsis occur 2-3 days after the onset of sepsis that characterized by the decrease of left ventricular ejection fraction of the heart [6]. Echocardiography is the most commonly performed to assess cardiac dysfunction using but it requires accurate subjective ability by a trained professional [7].

The detection of myocardial dysfunction using biochemical markers is the easiest modality to perform.
In cardiac muscle necrosis, intracellular proteins will enter the interstitial space and systemic circulation through local microvascular and lymphatic flow. This intracellular heart protein is detected as a biochemical marker of heart muscle damage. Troponin is a biochemical marker for myocardial disorders that have high sensitivity that can even show minor myocardial injury [7]. Another laboratory marker associated with critical illness is the level of lactate in the blood. Several studies have suggested that increased lactate levels are associated with an increased response to stress. Lactate examination itself is an easy and fast examination, so this examination has been widely studied to assess the prognosis of critically ill patients, especially patients with heart defects [8].

A study regarding lactate levels in infants undergoing cardiac surgery has shown that lactate levels above $5.8 \mathrm{mmol} / \mathrm{dl}$ have a sensitivity of $67 \%$ and a specificity of $64 \%$ for mortality [9]. Another study also showed that lactate levels $\geq 4 \mathrm{mmol} / \mathrm{L}$ are a cut-off predictor of mortality in children with septic shock [10]. In a study conducted on children in pediatric intensive care rooms, lactate levels $>3.3 \mathrm{mmol} / \mathrm{L}$ had high sensitivity and specificity to myocardial dysfunction, namely $90.9 \%$ and $89.9 \%$ [11]. Myocardial dysfunction is often accompanied by a state of metabolic acidosis, 
liver damage, kidney damage, and anemia. Therefore, the aim of this study was to prove the role of lactate and other laboratory markers in the early assessment of myocardial dysfunction.

\section{Methods}

An observational cohort study was conducted on children who admitted in the Pediatric Intensive Care Unit (PICU) H. Adam Malik General Hospital Medan, periods in April - September 2020. Subjects that fulfilled inclusion and exclusion criteria will be given an explanation about the condition of the disease then asked for parents' approval. The study was approved by the Health Ethics Committee from the Faculty of Medicine, Universitas Sumatera Utara Medan. Patients with heart disease, either congenital or acquired, based on anamnesis, physical examination, or chest X-ray were excluded from the study.

Demographic data such as age, gender, nutritional status, medical history, physical examination, and diagnosis are recorded. Blood samples are taken for a complete blood count, renal function test, liver function test, lactate, blood gas analysis, and troponin I (Tnl) within $48 \mathrm{~h}$ PICU admission. Further division according to $\mathrm{Tnl}$ level cut value of $0.4 \mathrm{ng} / \mathrm{mL}$ into other two groups: Group with subtle myocardial dysfunction (SMD) having $\mathrm{Tnl}$ level $\geq 0.4 \mathrm{ng} / \mathrm{ml}$ and group nonSMD without myocardial dysfunction having Tnl level $<0.4 \mathrm{ng} / \mathrm{ml}$. Then, the subject was followed up during treatment until moved to the ward or died.

Univariate analysis was done to determine the distribution of characteristics of critically ill children in PICU. Categorical variables were expressed as frequency and percentage, and non-normality data distribution caused numeric variables were expressed as median (minimalmaximal). Bivariate analysis was done using MannWhitney test. The Spearman correlation test was used to examine the association between troponin levels and pediatric logistic organ dysfunction score (PELOD)-2 score. Receiver operating characteristic curve analysis (ROC) was used for the identification of optimal intersection points and to check for discrimination and the area under the curve is compared. Data were analyzed using Statistical Package for the Social Sciences version 22.

\section{Results}

From this study, of all 55 subjects was recruited, SMD was found in 23 subjects $(41.8 \%)$. Mortality was
Table 1: Subject characteristics

\begin{tabular}{ll}
\hline Indicator & $\mathrm{n}=55$ \\
\hline Gender (n, \%) & $29(52.7)$ \\
Boys & $26(47.3)$ \\
Girls & \\
Age (n, \%) & $21(38.2)$ \\
Under 1 year old & $10(18.1)$ \\
$1-5$ years old & $10(18.1)$ \\
$6-10$ years old & $14(25.6)$ \\
$11-18$ years old & $11(3-55)$ \\
Body weight (kg),median (min-max) & $84(44-165)$ \\
Body height (cm),median (min-max) & $10(18.2)$ \\
Nutritional status (n, \%) & $4(7.3)$ \\
Severe malnutrition & $39(70.9)$ \\
Mild-moderate malnutrition & $2(3.6)$ \\
Well-nourished & $19(34.5)$ \\
Overweight & $20(36.4)$ \\
PICU admission indication (n, \%) & $5(9.1)$ \\
Respiratory disorder & $4(7.3)$ \\
Neurological disorder & $7(12.7)$ \\
Circulation disorder & \\
Nephrology disorder & $26(49.1)$ \\
Postoperative management & $29(50.9)$ \\
Outcome (n, \%) & $23(41.8)$ \\
Move to the ward & $32(58.2)$ \\
Death & \\
Myocardial dysfunction (n, \%) &
\end{tabular}

found in $29(52.7 \%)$ subjects. Baseline characteristics of study subjects are shown in Table 1.

Table 2 shows the association between each laboratory marker and subtle myocardial dysfunction. Laboratory marker in SMD that has significant finding was lactate (median $3.2 \mathrm{ng} / \mathrm{ml} ; \mathrm{p}=0.003$ ), aspartate aminotransferase (AST) (median $84 \mathrm{U} / \mathrm{l} ; \mathrm{p}=0.028$ ), alanine aminotransferase (ALT) (median $85 \mathrm{U} / \mathrm{l}$; $\mathrm{p}=0.01$ ), and hemoglobin (median $8.9 \mathrm{~g} / \mathrm{dl} ; \mathrm{p}=0.001$ ). Lactate level had well power as a predictive factor of SMD in critically ill children with lactate level cut off point was $2.5 \mathrm{ng} / \mathrm{mL}(74 \%$ sensitivity and $72 \%$ specificity) (Figure 1).

Table 2: Association between laboratory marker and SMD

\begin{tabular}{|c|c|c|c|}
\hline \multirow[t]{2}{*}{ Laboratory marker } & SMD & Non-SMD & \multirow[t]{2}{*}{$\mathrm{p}^{*}$} \\
\hline & $\mathrm{n}=23$ & $n=32$ & \\
\hline \multicolumn{4}{|l|}{ Hematology } \\
\hline Hemoglobin ( $\mathrm{g} / \mathrm{dl})$, median (min-max) & $7.2(5.5-10.5)$ & $9.3(5.2-10.8)$ & 0.001 \\
\hline WBC $\left(10^{3} / \mathrm{mm}^{3}\right)$, median (min-max) & $13.5(2.0-32.8)$ & $12.9(6.1-37.8)$ & 0.94 \\
\hline Platelet $\left(10^{3} / \mathrm{mm}^{3}\right)$, median (min-max) & $173(7-657)$ & $187(7-501)$ & 0.65 \\
\hline \multicolumn{4}{|l|}{ Blood gas analysis } \\
\hline $\mathrm{pH}$, median (min-max) & $7.37(7.15-7.56)$ & $7.36(6.9-7.56)$ & 0.56 \\
\hline $\mathrm{PaO}_{2}(\mathrm{mmHg})$, median (min-max) & $148(93-176)$ & $129(93-180)$ & 0.26 \\
\hline $\mathrm{PCO}_{2}(\mathrm{mmHg})$, median (min-max) & $39(22-95)$ & $40(21-90)$ & 0.32 \\
\hline \multicolumn{4}{|l|}{ Liver function test } \\
\hline AST (U/L), median (min-max) & $84(26-166)$ & $41(16-98)$ & 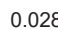 \\
\hline ALT (U/L), median (min-max) & $85(36-165)$ & $49(32-100)$ & 0.01 \\
\hline \multicolumn{4}{|l|}{ Renal function test } \\
\hline Ureum, median (min-max) & $54(33-125)$ & $52(30-240)$ & 0.69 \\
\hline Creatinine, median (min-max) & $0.7(0.09-21.2)$ & $0.5(0.16-9,1)$ & 0.12 \\
\hline Lactate $(\mathrm{ng} / \mathrm{ml})$, median (min-max) & $3.2(0.8-10.4)$ & $0.31(0.19-1.9)$ & 0.003 \\
\hline
\end{tabular}

Table 3 shows the correlation between $\mathrm{Tnl}$ and other laboratory marker with PELOD-2 scores. From this study, there was significant positive correlation between Tnl levels, AST, ALT, lactate, and PELOD-2 scores $(r=0.68, p<0.001 ; r=0.32, p=0.015 ; r=0.41$, $p=0.002 ; r=0.38, p=0.004$, respectively). Significant negative correlation was also found between hemoglobin and PELOD-2 scores $(r=-0.53, p<0.001)$. Subject with SMD also has significant association with mortality $(p<0.001)$. 


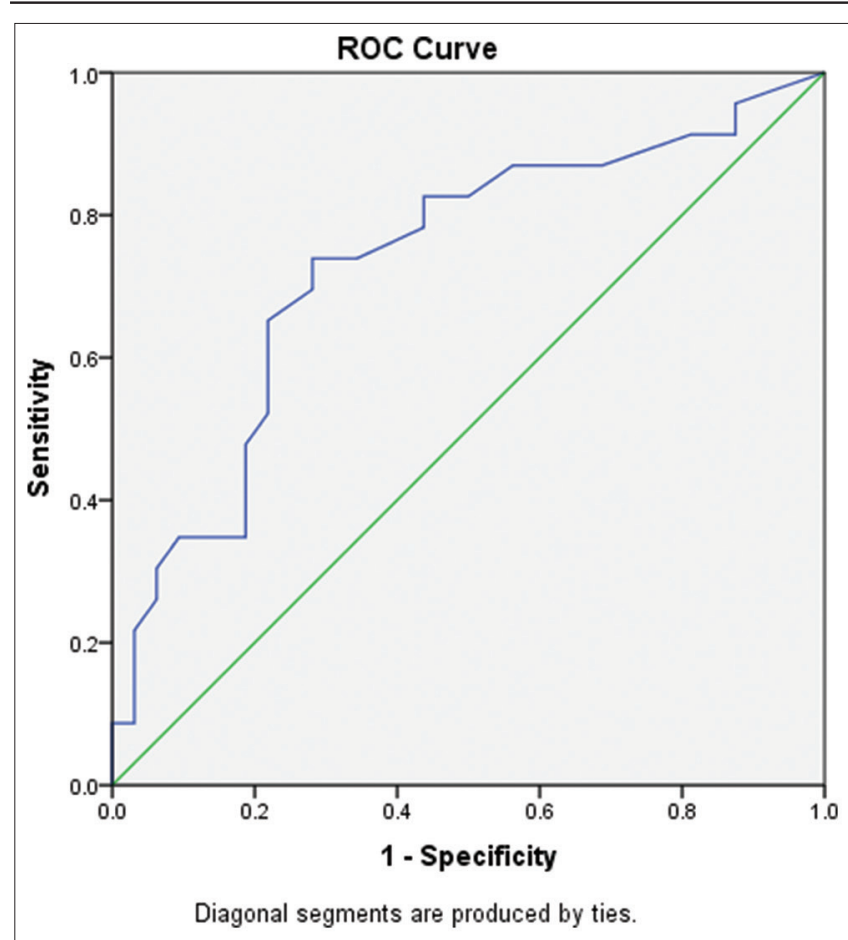

Figure 1: Receiver operating curve of lactate level (AUC $73.2 \%, p=0.004,95 \%$ Cl 0.59-0.87)

\section{Discussion}

There was several studies that show critically ill children have significantly higher levels of troponin when compared to healthy children [12]. In PICU patients, physiological stress can cause decreased myocardial oxygen delivery or increased myocardial oxygen demand, this imbalance was a predisposition of critically ill patients to develop acute thrombosis that may explain the increased risk of myocardial injury [13]. Tantawy et al. show the incidence of SMD among PICU patients was found to be $17.5 \%$, where reported incidence of myocardial dysfunction associated with sepsis in the PICU ranged from $4.5-75 \%$. This high variability is explained by various inclusion and exclusion criteria that were adopted by different authors [11]. This study shows there was $41.8 \%$ patient that has myocardial dysfunction

Table 3: Correlation between troponin and laboratory marker with PELOD-2 Score

\begin{tabular}{|c|c|c|c|}
\hline Laboratory marker & Median (min-max) & $\mathrm{r}$ & $\mathrm{p}^{\star *}$ \\
\hline \multicolumn{4}{|l|}{ Hematology } \\
\hline Hemoglobin (g/dl), median (min-max) & $8.9(5.2-10.8)$ & -0.53 & $<0.001$ \\
\hline WBC $\left(10^{3} / \mathrm{mm}^{3}\right)$, median (min-max) & $13.5(2.0-37.8)$ & 0.1 & 0.6 \\
\hline Platelet $\left(10^{3} / \mathrm{mm}^{3}\right)$, median (min-max) & $177(7-657)$ & -0.3 & 0.22 \\
\hline \multicolumn{4}{|l|}{ Blood gas analysis } \\
\hline $\mathrm{pH}$, median (min-max) & $7.37(6.9-7.56)$ & 0.1 & 0.68 \\
\hline $\mathrm{PaO}_{2}(\mathrm{mmHg})$, median (min-max) & $137(93-180)$ & 0.1 & 0.74 \\
\hline $\mathrm{PCO}_{2}(\mathrm{mmHg})$, median (min-max) & $38(21-95)$ & 0.18 & 0.17 \\
\hline \multicolumn{4}{|l|}{ Liver function test } \\
\hline AST (U/L), median (min-max) & $45(26-166)$ & 0.32 & 0.015 \\
\hline ALT (U/L), median (min-max) & $52(32-165)$ & 0.41 & 0.002 \\
\hline \multicolumn{4}{|l|}{ Renal function test } \\
\hline Ureum, median (min-max) & $54(33-240)$ & 0.1 & 0.67 \\
\hline Creatinine, median (min-max) & $0.5(0.09-21.2)$ & 0.16 & 0.23 \\
\hline Lactate (ng/ml), median (min-max) & $2.5(0.8-10.4)$ & 0.38 & 0.004 \\
\hline Troponin I (ng/ml), median (min-max) & $0.5(0.19-1.9)$ & 0.68 & $<0.001$ \\
\hline
\end{tabular}

It has been proven that $\mathrm{Tnl}$ is a reliable indicator for myocardial injury detection in pediatrics [14]. In this study, SMD was defined by $\mathrm{Tnl}$ level $\geq 0.4 \mathrm{ng} / \mathrm{mL}$, following a previous study by Tantawy et al., with significant association with liver injury and anemia. Mechanism of anemia that suggested was hemoglobin production is inhibited due to associated inflammation with increased levels of hepcidin-25 in sepsis [15]. Elevations of serum Tnl levels are common ( $74 \%$ overall) in patients with liver injury of various etiologies. Cardiovascular collapse and sepsis were also potential causes of elevated Tnl levels and liver enzymes [16]. Sepsis in an experimental animal model found that increased mitochondrial activity of FOF1ATPase could contribute to bioenergetic failure in the liver and activation of adrenoceptors on Kupffer cells increases the release of tumor necrosis factor and nitric oxide results in more mitochondrial damage [17].

This study found that high lactate levels > $2.5 \mathrm{ng} / \mathrm{mL}$ can be considered as predictors SMD in pediatric sepsis patients. A previous study shows that lactate has a specificity of $89.5 \%$ and a sensitivity of $90.5 \%$ in detecting SMD [11]. No other study was found to prove lactate as a predictor in myocardial dysfunction, but there were several studies that show lactate and its association with mortality. Kawase et al. stated that lactate can be used as a predictor for mortality in intensive care unit with sensitivity and specificity were $60.2 \%$ and $74.6 \%$, respectively [18]. Zymlinski et al. also stated that blood lactate on admission predicted poor outcome in patients with acute heart failure (hazard ratio 1.24) [19].

The PELOD-2 was used to assess the organ dysfunction in the child. Karam et al. found that changes in the PELOD-2 score were associated with the likelihood of death [20]. Troponin is a cardiac myofibril compound that was investigated its association with myocardial dysfunction in sepsis. Myocardial dysfunction, showed by impaired left ventricular systolic and diastolic function, considered as a complication of early sepsis, especially in septic shock patients. Impaired blood flow will decrease the perfusion of the myocardium, resulting in myocardial dysfunction and release of troponins from cardiac myocytes [21]. Higher troponin levels were associated with more severe clinical features and poorer outcomes. A case-control study by Hassan et al. shows that troponin levels were associated with patient severity and positively correlated with PIM2 scores $(r=0.67$; $p<0.05$ ) [12]. Another study by Lodha et al. shows that troponin levels on admission were positively correlated with the PIM2 score $(r=0.51, p=0.03)$ [22]. A similar result was found in this study with a strong correlation between Tnl level and PELOD-2 score and subject with SMD also has a significant association with mortality.

Higher mortality for sepsis with myocardial dysfunction versus sepsis without myocardial 
dysfunction reported. Case-control study by Lautz et al. shows that subject with myocardial dysfunction has higher mortality compared with no myocardial dysfunction (52\% vs. $17 \%$, p < 0.001) [23]. Different result shows by Tantawy et al. that no significant difference of mortality between SMD and non-SMD subject $(p=0.36)$ [11]. This study shows that there was a significant association between SMD and mortality.

Some of the limitations in this study were the wide variety of disease course and severity when the patient was admitted in PICU, resulting in very diverse data. High mortality in this study rate makes the exact correlation of a different variable with mortality difficult. In addition, troponin measurement should be followed by tests such as echocardiography or another hemodynamic measurement to assess myocardial dysfunction. It is hoped that early assessment of myocardial dysfunction can help optimal intervention for cardiac disorders in critically ill children.

\section{Conclusion}

Lactate is a good predictor for SMD in critically ill children with moderate power of sensitivity and specificity. Myocardial dysfunction should be suspected in children with a high lactate level $>2.5 \mathrm{ng} / \mathrm{ml}$ since there has been a significant association between SMD and mortality.

\section{References}

1. Stijn I, Federico P, Jeffrey L. The effect of pathophysiology on pharmacokinetics in the critical ill patient-concept appraised by the example of antimicrobial agents. Adv Drug Deliv Rev. 2014;77:3-11.

PMid:25038549

2. Wong HR, Nowak JE, Standage SW, Oliveira CF. Sepsis. In: Fuhrman BP, Zimmerman JJ, Carcillo JA, Clark RS, Relvas M, Rotta AT, et al., editor. Pediatric Critical Care. $4^{\text {th }}$ ed. Philadelphia, PA: Elsevier; 2011. p. 1413-29.

3. Riley C, Wheeler DS. Prevention of sepsis in children: A new paradigm for public policy. Crit Care Res Pract. 2011;2012:437139.

PMid:22216408

4. Hadinegoro SR, Chairulfatah A, Latief A, Alam A, Pudjiadi A, Malisie RF. Pedoman Nasional Pelayanan Kedokteran Ikatan Dokter Anak Indonesia: Diagnosis dan Tatalaksana Sepsis Pada Anak. Jakarta: Ikatan Dokter Anak Indonesia; 2016. p. 1-7. https://doi.org/10.14238/sp10.2.2008.139-44

5. Gerlach AT, Murphy C. An update on nutrition support in the critically ill. J Pharm Pract. 2010;24(1):70-7.

PMid:21507876
6. Wu JR, Chen IC, Dai ZK, Hung JF, Hsu JH. Early elevated B-type natriuretic peptide levels are associated with cardiac dysfunction and poor clinical outcome in pediatric septic patients. Acta Cardiol Sin. 2015;31(6):485-93. PMid:27122912

7. Samsu N, Sargowo D. The sensitivity and specificity of troponins $\mathrm{T}$ and $\mathrm{I}$ in the diagnosis of acute myocardial infarction. Maj Kedokt Indon. 2007;57:363-72.

8. Lazzari S, Mostacelli D, Codari F, Salmona M, Morbidelli M, Diomede L. Colloidal stability of polymeric nanoparticles in biological fluids. J Nanopart Res. 2012;14(6):920. https://doi. org/10.1007/s11051-012-0920-7

9. Rocha TS, Silveira AS, Botta AM, Ricachinevsky CP, Dalle Mulle L, Nogueira A. Serum lactate as mortality and morbidity marker in infants after Jatene's operation. Rev Bras Cir Cardiovasc. 2010;25(3):350-8.

PMid:21103743

10. Choudhary R, Sitaraman S, Choudhary A. Lactate clearance as the predictor of outcome in pediatric septic shock. J Emerg Trauma Shock. 2017;10(2):55-9. https://doi.org/10.4103/jets. jets_103_16 PMid:28367008

11. Tantawy AE, Hamza HS, Saied MH, Elgebaly HF. Lactate and other clinicolaboratory predictors for subtle myocardial dysfunction in pediatric intensive care unit. Egypt Heart J. 2012;64:247-53. https://doi.org/10.1016/j.ehj.2012.06.005

12. Hassan B, Morsy S, Siam A, Ali AS, Abdo M, Al Shafie M, et al. Myocardial injury in critically III children: A case control study. ISRN Cardiol. 2014;2014:919150. https://doi. org/10.1155/2014/919150 PMid:24660069

13. Boyette LC, Manna B. Physiology, myocardial oxygen demand In: Stat Pearls. Treasure Island, FL: Stat Pearls Publishing; 2020.

14. Konstantinides S, Geibel A, Olschewski M, Kasper W, Hruska N Jäckle $S$, et al. Importance of cardiac troponins $I$ and $T$ in risk stratification of patients with acute pulmonary embolism. Circulation. 2002;106(10):1263-8. https://doi.org/10.1161/01. cir.0000028422.51668.a2 PMid:12208803

15. van Eijk LT, Kroot JJ, Tromp M, van der Hoeven JG, Swinkels DW, Pickkers P. Inflammation induced hepacidin-25 associated with the development of anemia in septic patients: An observational study. Crit Care. 2011;15(1):R9. https://doi.org/10.1186/cc9408 PMid:21219610

16. Parekh NK, Hynan LS, De Lemos J, Lee WM, Acute Liver Failure Study Group. Elevated troponin I levels in acute liver failure: Is myocardial injury an integral part of acute liver failure? Hepatology. 2007;45(6):1489-95. https://doi.org/10.1002/ hep. 21640 PMid:17538968

17. Huang JT, Zhuy YM, Lu ZN. The analysis of the relationship between creatine kinase and troponin. Chin J Evid Based Pediatric. 2011;16(31):36.

18. Kawase T, Toyofuku M, Higashihara T, Okubo Y, Takahashi L, Kagawa $\mathrm{Y}$, et al. Validation of lactate level as a predictor of early mortality in acute decompensated heart failure patients who entered intensive care unit. J Cardiol. 2015;65(2):164-70. https://doi.org/10.1016/j.jjcc.2014.05.006 PMid:24970716

19. Zymlinski R, Biegus J, Sokolski M, Siwołowski P, NawrockaMillward S, Todd J, et al. Increased blood lactate is prevalent and identifies poor prognosis in patients with acute heart failure without overt peripheral hypoperfusion. Eur J Heart Fail. 2018;20(6):1011-8. https://doi.org/10.1002/ejhf.1156 
PMid:29431284

20. Karam O, Demaret P, Duhamel A, Shefler A, Spinella PC, Stanworth SJ, et al. Performance of the PEdiatric logistic organ dysfunction-2 score in critically ill children requiring plasma transfusions. Ann Intensive Care. 2016;6(1):98. https://doi. org/10.1186/s13613-016-0197-6

PMid:27714707

21. Kakihana $\mathrm{Y}$, Ito $\mathrm{T}$, Nakahara $\mathrm{M}$, Yamaguchi $\mathrm{K}$, Yasuda $\mathrm{T}$. Sepsis induced myocardial dysfunction: Pathophysiology and management. J Intensive Care. 2016;4:22. https://doi.

\section{org/10.1186/s40560-016-0148-1}

PMid:27011791

22. Lodha R, Arun S, Vivekanandhan S, Kohli U, Kabra SK. Myocardial cell injury is common in children with septic shock. Acta Paediatr. 2009;98(3):478-81. https://doi.org/10.1111/j.1651-2227.2008.01095.x PMid: 18976355

23. LautzA, Wong H, Ryan T, Statile C. 1566: Myocardial dysfunction in pediatric septic shock: Persevere ii risk and mortality. Crit Care Med. 2020;48(1):759. https://doi.org/10.1097/01. ccm.0000648172.61303.e0 